\title{
Discriminative Immunophenotype of Bronchoalveolar Lavage CD4 Lymphocytes in Sarcoidosis
}

\author{
Marie-Nathalie Kolopp-Sarda, Chantal Kohler, Anne Kennel De March, \\ Marie-Christine Béné, and Gilbert Faure \\ Laboratoire d'Immunologie, Faculté de Médecine and CHU de Nancy, France
}

\begin{abstract}
SUMMARY: The diagnosis of pulmonary sarcoidosis relies in part on the observation of alveolar CD4 ${ }^{+}$lymphocytosis. However, this criterion is not fully discriminative because this anomaly is also found in other types of lung diseases. Among other possible distinctive criteria, we investigated the expression of lymphocyte-addressing molecules, which could differ according to the pathophysiology of lung diseases. We investigated CD103 ( $\alpha^{\mathrm{E}} \beta 7$ integrin, CD103- $\left.\beta 7\right)$, reported to be both expressed on intra-epithelial lymphocytes in mucosal areas, including bronchi, and possibly involved in the recruitment of alveolar lymphocytes. The expression of CD103 was examined on bronchoalveolar lavage lymphocytes from 93 consecutive patients, including 34 patients with CD4 ${ }^{+}$lymphocytosis. For all patients, the expression of CD19, CD3, CD4, CD8, CD57, LFA1, DR, and CD103 was assessed by flow cytometry. Sarcoidosis seemed remarkably characterized by the lack of CD103 expression on the predominant $\mathrm{CD}^{+}$subset. Statistically significant differences were found between patients with sarcoidosis, with other types of CD4 ${ }^{+}$ lymphocytosis, and with other lung disorders in the $\mathrm{CD}_{103^{+}}$cell levels and in the CD103/CD4 ratio. Combined use of the CD4/CD8 ratio $(>2.5)$ and the CD103/CD4 ratio $(<0.31)$ to assess bronchoalveolar lavage lymphocytes is a promising new tool for the diagnosis of sarcoidosis. (Lab Invest 2000, 80:1065-1069).
\end{abstract}

$I$ mmune protection of the lungs involves both nonspecific and specific humoral and cellular responses (Jeffery and Corrin, 1984; Nicod, 1999). The cellular responses are provided by several types of immunocompetent cells, including macrophages, mast cells, eosinophils, neutrophils, and lymphocytes (Kolopp-Sarda et al, 1994; Pabst and Gehrke, 1992; Pabst and Tschernig, 1995). In normal conditions, as in other mucosal areas, nonspecific and specific immune responses in the lung are efficient and noninflammatory (Brandtzaeg, 1996; Jeffery and Corrin, 1984; Samet and Utell, 1991), and only small numbers of lymphocytes are present in lung alveoli. In respiratory diseases, inappropriate or ill-regulated immune responses may develop, involving the bronchi, lung parenchyma, and, in some instances, alveoli (Agostini et al, 1993).

The widely used technique of bronchoalveolar lavage (BAL) is the least invasive tool to assess the immune status of the lung, and aids in the diagnosis and/or prognosis of respiratory diseases (Agostini et al, 1993; Poulter et al, 1992; Semenzato, 1991). In normal individuals, BAL have low cell counts and more than $90 \%$ of the cells are macrophages (Merchant et al, 1992). In BAL from patients with lung diseases, the global cell count is often increased, and BAL lymphocytes and/or polymorphonuclears may be present in large proportions. The clinical use of $\mathrm{BAL}$ in the diagnosis of lung pathologies is directly related to the

Received March 10, 2000.

Address reprint requests to: Dr. M. N. Kolopp-Sarda, Laboratoire d'Immunologie, Faculté de Médecine, BP 184, 54500 Vandoeuvre-lèsNancy, France.Fax: 333834460 22; E-mail:mkolopps@grip.u-nancy.fr cell count and immunophenotype of the BAL lymphocytes (Agostini et al, 1993). Anomalies detected in BAL may allow early or confirmatory diagnosis and/or prognostic information (Agostini et al, 1993; Poulter et al, 1992).

BAL hyperlymphocytosis, observed in viral infections, some forms of alveolitis, interstitial syndromes, and sarcoidosis (Agostini et al, 1993; Poulter et al, 1992; Semenzato, 1991), may involve different T cell subsets. $\mathrm{CD}^{+}{ }^{+}$cells represent the major $\mathrm{T}$ cell subset in most cases of sarcoidosis, and the demonstration of an increased CD4/CD8 ratio has been proposed as a diagnostic tool for pulmonary sarcoidosis. This criterion has been criticized because CD4 ${ }^{+}$lymphocytosis may also be observed in other types of lung diseases (Agostini et al, 1993), and although the specificity of an elevated CD4/CD8 ratio is high in sarcoidosis, the sensitivity of this marker is seldom more than 50\% (Costabel, 1997; Costabel et al, 1992).Thus far, the search for other pathognomonic criteria allowing the discrimination of sarcoidosis patients from patients with $\mathrm{CD}^{+}{ }^{+}$alveolar lymphocytosis has been disappointing.

The mechanisms by which $T$ cells reach lung alveoli, although not well known (Krug et al, 1998; Pabst and Tschernig, 1995), are likely to depend upon specific addressing signals. Because the respiratory tract is part of the mucosal immune system (Krug et al, 1998; Pabst and Tschernig, 1995), the addressing signals could involve CD103 ( $\alpha^{\mathrm{E}} \beta 7$ integrin, CD103- $\beta 7$ ) (Cepek et al, 1995; Cerf-Bensussan et al, 1987), which was first described on human gut intra-epithelial lymphocytes. CD103 has also been reported to be expressed on lymphocytes located in the epithelium of 
mammary glands, the uterus, bronchi, and bronchial glands (Cepek et al, 1995; Cerf-Bensussan et al, 1987). CD103 could be involved in the recruitment of lymphocytes to or through lung epithelial cells (Shaw and Brenner, 1995), as is suggested by a study performed with five healthy subjects, demonstrating the expression of CD103 on $69 \%$ of $\mathrm{CD}^{+}$and $29 \%$ of $\mathrm{CD}^{+}$BAL lymphocytes (Erle et al, 1994). If CD103 is involved in transcytosis, these proportions might be modified in patients with $\mathrm{CD}^{+}$alveolar lymphocytosis, perhaps in different fashions depending on the pathophysiology of the disease.

We investigated this hypothesis in 93 consecutive BAL samples sent for immunophenotyping to our laboratory, and found evidence that this surface marker is a discriminative tool for the diagnosis of sarcoidosis in patients with $\mathrm{CD}^{+}{ }^{+}$lymphocytosis.

\section{Results}

Comparison of BAL lymphocytosis showed significant differences between patients and controls (Table 1). Group 1 patients had the highest proportions of lymphocytes. The mean percentages of all lymphocyte subsets investigated in each group of patients were compared with those of controls. As expected, major differences were noted for CD4 and CD8 subsets. Patients in both Groups 1 and 2 differed significantly from controls and from Group 3 patients $(p<0.0001$ for both CD4 and CD8). CD4/CD8 ratios (mean \pm SD) were significantly higher in Groups $1(8.9 \pm 5.5)$ and 2 $(5.9 \pm 3.0)$ than in Groups $3(1.1 \pm 0.6)$ and 4 (1.3 \pm $0.5)(p<0.0001)$. The mean percentage of LFA1 was significantly higher in patients compared with controls $(p<0.05)$. No differences in CD57 or DR expression were found between the four groups. CD19 ${ }^{+}$lymphocytes were never observed.

Similar proportions of $\mathrm{CD} 103^{+}$cells were observed in Groups 2, 3, and 4 (Fig. 1). This was in sharp contrast with the significantly lower proportion of this subset in Group 1 ( $p<0.0001$ for all comparisons of Group 1 with each of the three other groups). Comparing the level of CD103 expression in sarcoidosis BAL with all other patients (pool of Groups 2, 3, and 4, $n=75)$, we observed a statistically significant difference $(p<0.0001)$ between sarcoidosis $(9.5 \pm 6.0 \%)$ and all other BAL (33.8 $\pm 17.1 \%)$.
Because five patients in whom the diagnosis of sarcoidosis had been excluded had $\mathrm{CD}_{103^{+}}$levels within the range of sarcoidosis patients (less than $16 \%$ ), we examined the CD103/CD4 ratio. As shown in Figure 2, this ratio significantly discriminates between the four groups of patients tested. Sarcoidosis patients were statistically different from each of the three other groups $(p<0.0001)$. Patients with CD4 ${ }^{+}$lymphocytosis of other etiology also differed both from Group 3 patients $(p<0.01)$ and from controls $(p=$ 0.005). Group 3 patients had similar CD103/CD4 values to controls.

According to these results, a CD103/CD4 ratio threshold to be discriminative for sarcoidosis was set at the mean +2 SD of Group 1, ie, 0.31 . All sarcoidosis patients fulfilled this criterion. Only one patient from Group 2 had a CD103/CD4 ratio below 0.31 . The only patient in Group 3 who had a CD4/CD8 ratio of 2.6 did not meet the criterion for lymphocytosis $(8 \%$ of $\mathrm{BAL}$ cells) and had a CD103/CD4 ratio of 0.65 . The combined sensitivity of a CD103/CD4 ratio $<0.31$ and CD4 ${ }^{+}$lymphocytosis (defined as a CD4/CD8 ratio $\geq$ $2.5)$ was $96 \%$ for the diagnosis of sarcoidosis.

\section{Discussion}

This study reports on BAL lymphocyte immunophenotyping and demonstrates the effective use of CD103 expression as an additional discriminative tool to distinguish sarcoidosis patients from patients with $\mathrm{CD}^{+}{ }^{+}$lymphocytosis. Indeed, CD4 ${ }^{+}$lymphocytosis, one of the major characteristics of sarcoidosis, can also be observed in other lung diseases (Agostini et al, 1993), as was the case in the 16 patients from Group 2 reported here. In this population of non-sarcoidosis patients, the expression of CD103 was noted on $32.8 \pm 3.7 \%$ of lymphocytes, ie, at least $30 \%$ of CD4 ${ }^{+}$ cells, whereas $\mathrm{CD}^{+}{ }^{+}$lymphocytes from sarcoidosis patients almost completely lacked CD103 expression.

According to previously reported criteria (reviewed in Costabel, 1997; Costabel et al, 1992), a diagnosis of sarcoidosis could have been suspected in 16 of 18 of the sarcoidosis patients based on a CD4/CD8 ratio more than 3.5, but this was also the case for 12 of 16 of the patients with $\mathrm{CD}^{+}{ }^{+}$lymphocytosis of a different etiology. Therefore, a correct diagnosis of sarcoidosis

Table 1. Comparative Analysis of Bronchoalveolar Lavage Between Patients and Controls (mean \pm SE)

\begin{tabular}{lcccc}
\hline & Sarcoidosis & CD4+ Lymphocytosis & Other Pathologies & Controls \\
\hline \% lymphocytes & $37.1 \pm 3.9^{* * *}$ & $30.5 \pm 3.6^{* * *}$ & $27.9 \pm 3.1^{* *}$ & $8.5 \pm 1.2$ \\
$\%$ CD3 & $72.0 \pm 3.9^{* *}$ & $64.3 \pm 3.5^{\star}$ & $62.9 \pm 2.8$ & $53.4 \pm 4.2$ \\
$\%$ CD4 & $63.2 \pm 3.4^{* * *}$ & $54.9 \pm 4.4^{* * *}$ & $29.9 \pm 2.2$ & $28.2 \pm 3.2$ \\
$\%$ CD8 & $8.7 \pm 0.9^{* * *}$ & $10.9 \pm 1.2^{\star * *}$ & $31.0 \pm 2.0$ & $24.1 \pm 2.5$ \\
$\%$ CD57 & $8.7 \pm 0.9$ & $6.6 \pm 1.7$ & $6.9 \pm 1.0$ & $4.4 \pm 1.2$ \\
$\%$ CD103 & $9.5 \pm 1.4^{* * *}$ & $32.8 \pm 3.7$ & $35.4 \pm 2.6$ & $28.5 \pm 3.6$ \\
$\%$ LFA1 & $69.4 \pm 3.9^{* *}$ & $62.9 \pm 3.6^{*}$ & $63.9 \pm 2.6^{*}$ & $51.5 \pm 4.9$ \\
$\%$ DR & $16.1 \pm 5.5$ & $7.7 \pm 1.9$ & $13.7 \pm 2.3$ & $8.3 \pm 2.2$ \\
\hline
\end{tabular}

*** $p<0.0001 ;{ }^{* \star} p \leq 0.01 ;{ }^{*} p<0.05$.

Statistically significant differences indicated relate to comparison with the control group. 


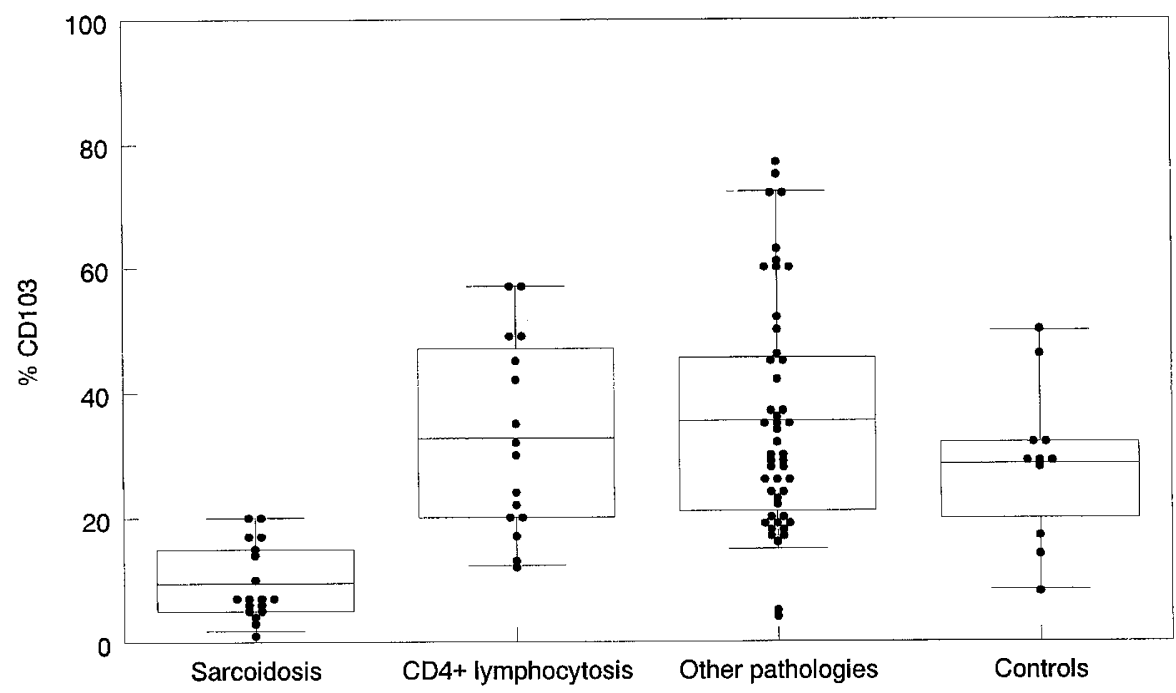

\section{Figure 1.}

Individual levels of $\mathrm{CD} 103^{+}$lymphocytes in bronchoalveolar lavage from the four groups of subjects tested. Box whiskers indicate the $25^{\text {th }}$ and $75^{\text {th }}$ percentiles $($ box), mean (horizontal bar), and the $5^{\text {th }}$ and $95^{\text {th }}$ percentiles (vertical topped bars).

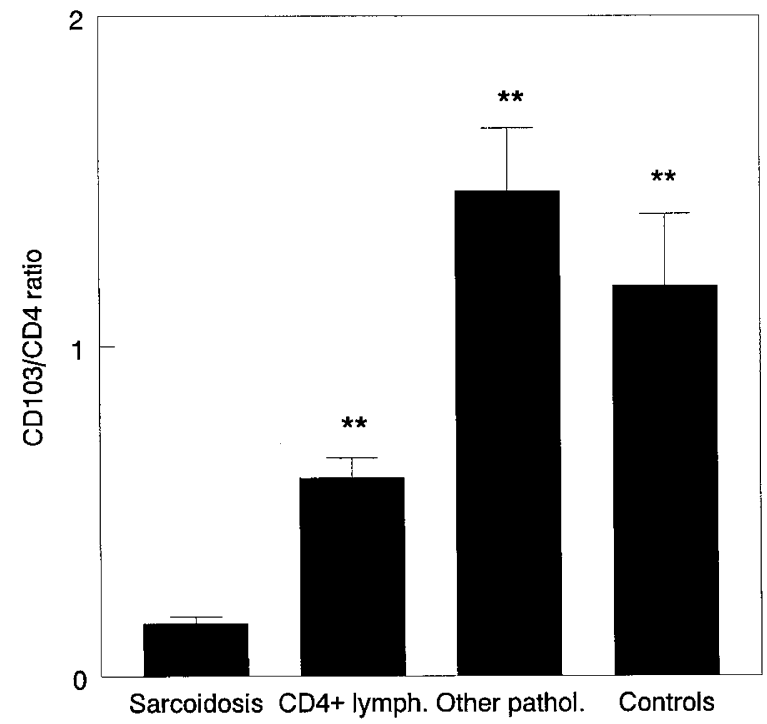

Figure 2.

Comparative mean levels (topped by $\mathrm{SE}$ ) of the CD103/CD4 ratio among bronchoalveolar lavage lymphocytes in patients of the four groups studied. Statistical significance is shown for comparisons with the group of sarcoidosis patients $\left({ }^{* *} p<0.0001\right)$.

could only have been achieved in $47 \%$ of this series of $\mathrm{CD}^{+}$lymphocytosis patients, ie, with a sensitivity similar to that reported in the literature. Combined use of the criteria proposed here, a high CD4/CD8 ratio ( $\geq$ $2.5)$ and a low CD103/CD4 ratio $(<0.31)$, allowed a correct diagnosis on BAL in all of the sarcoidosis patients in this study, with a sensitivity of $96 \%$.

This study also investigated whether CD103 could be an addressing molecule involved in the recruitment of BAL lymphocytes in lung diseases. Our data indicate that this hypothesis can be considered for approximately $30 \%$ of BAL lymphocytes, except in sarcoidosis.
Two explanations can be proposed for the lack of CD103 on sarcoidosis BAL lymphocytes. First, there could be a down-regulation of CD103 expression after the cells passed through the pneumocytes or bronchial epithelium. This type of mechanism has been reported for CD62L, the L-selectin, which guides peripheral blood lymphocytes to and through high endothelial venules and then disappears from relocated lymphocytes (Chen et al, 1995). This explanation is unlikely because at least $30 \%$ of BAL lymphocytes retain this molecule in other lung diseases. Second, because CD103 is a specific molecule of the mucosal immune system (Cerf-Bensussan et al, 1987), it could be that $\mathrm{CD} 4^{+} \mathrm{BAL}$ lymphocytes in sarcoidosis do not originate from mucosal inductive sites. This hypothesis is supported by the sarcoidosis model proposed by Semenzato (1991) suggesting $T$ cell redistribution from the peripheral blood and compartmentalization in the lung. Decreased levels of peripheral $\mathrm{CD}^{+}$lymphocytes parallel to increased levels of $\mathrm{CD}^{+}$BAL lymphocytes have been described in sarcoidosis (Chailleux et al, 1985). The absence of CD103 on $\mathrm{CD}^{+} \mathrm{BAL}$ lymphocytes in sarcoidosis would be consistent with a peripheral origin of these cells (CerfBensussan et al, 1987). An alternative adhesion molecule that could be used by peripheral lymphocytes to relocate in the lung is the $\alpha^{\mathrm{L}} \beta_{2}$ integrin LFA1 (CD11a/ CD18) (Erle et al, 1994; Krug et al, 1998), and we indeed observed significantly higher proportions of $\mathrm{LFA} 1^{+}$cells in sarcoidosis. From these data, it can be hypothesized that BAL lymphocytes originate from the systemic compartments of peripheral blood in sarcoidosis, and use LFA1 as addressing molecule. In other lung diseases, a mucosal origin for BAL lymphocytes could be suspected, with $\mathrm{CD}_{103}{ }^{+}$lymphocytes relocating from mucosal areas into the lung and eventually proliferating in response to local stimuli (Chilosi et al, 1988). 
Numerous studies have attempted to identify discriminative markers of sarcoidosis on lung and $B A L$ lymphocytes, and although examinations of the membrane expression of CD25, DR, CD29, VLA-1, and CD2 have been reported, none of these features seemed to be specific for sarcoidosis (Agostini et al, 1993; Krug et al, 1998; Poulter et al, 1992). Macrophages seem to have a peculiar immunophenotype in sarcoidosis, but are not classically examined in flow cytometry (Poulter et al, 1992). Increased IL1, IL2, and IFN $\gamma$ levels have been reported, but again, these are difficult to assess as a routine diagnostic (Poulter et al, 1992). Our data demonstrate that the combined use of CD4/CD8 and CD103/CD4 ratios provides a highly sensitive indicator of sarcoidosis in patients with $\mathrm{CD}^{+} \mathrm{BAL}$ lymphocytosis.

\section{Materials and Methods}

\section{Patients}

Ninety-three consecutive BAL samples addressed to our hospital laboratory for immunophenotyping were included in this study. Lymphocytosis was diagnosed for patients with lymphocytes being more than $10 \%$ of BAL cells; CD4 ${ }^{+}$lymphocytosis was diagnosed when the CD4/CD8 ratio was $\geq 2.5$.

Subsequent review of clinical and other diagnostic criteria in the patients' medical records allowed partition of the patients into four groups (Table 2). Group 1 (sarcoidosis) contained 18 patients with $\mathrm{CD}^{+}$lymphocytosis and confirmed pulmonary sarcoidosis according to clinical, radiological, and pathology criteria; Group 2 (CD4 ${ }^{+}$lymphocytosis) contained 16 patients presenting with $\mathrm{CD} 4^{+}$lymphocytosis in whom a diagnosis of sarcoidosis was excluded; Group 3 (other pathologies) contained 48 patients without CD4 ${ }^{+}$lymphocytosis presenting various types of lung pathologies or abnormal chest X-rays; and Group 4 (controls) contained 11 patients for whom BAL was prescribed on the basis of nonspecific clinical signs but was found to be normal (lymphocytes $<10 \%$, polymorphonuclear cells $<5 \%$ ).

\section{Immunophenotyping}

All BAL samples were tested on the day of bronchoalveolar lavage, within 4 hours of collection, using the aliquot of recovered liquid sent for cell count and immunophenotyping to the Immunology laboratory. After centrifugation at $600 \times \mathrm{g}$ for 10 minutes, the cell pellet was resuspended in $1 \mathrm{ml}$ of Hanks' medium (Imperial Laboratories, Abdington, United Kingdom). Cell suspensions were adjusted to $10^{7} \mathrm{cells} / \mathrm{ml}$. Differentials were performed after cytocentrifugation (Cytospin2; Shandon, Pittsburgh, Pennsylvania) and MayGrünwald Giemsa staining (Diff Quick; Baxter Dade, Dudingen, Switzerland). The proportions of macrophages, lymphocytes, neutrophils, and eosinophils were evaluated as percentages of total cell numbers.

Immunophenotyping was performed using $50 \mu \mathrm{l}$ aliquots of each cell suspension and monoclonal antibodies directed to CD19 (B4; Coulterclone, Coulter Corporation, Hialeah, Florida), CD3 (T3; Coulterclone), CD4 (T4; Coulterclone), CD8 (T8; Coulterclone), CD57 (NC1; Immunotech, Marseille, France), LFA1 (IOT16; Immunotech), DR (I0.2; Coulterclone), and CD103 (2G5; Immunotech). After labeling, the samples were fixed in $300 \mu$ of $1 \%$ paraformaldehyde in PBS and processed for flow cytometry using a Coulter XL (Coultronics, Hialeah, Florida).

Table 2. Clinical Characteristics of the Groups of Patients Included in This Study

\begin{tabular}{|c|c|c|c|}
\hline & $\begin{array}{c}\text { Age Range } \\
\text { (mean } \pm \text { SD) }\end{array}$ & Sex Ratio & Clinical Data \\
\hline Sarcoidosis (Group 1) $n=18$ & $\begin{array}{c}23-73 \\
(44 \pm 16)\end{array}$ & $10 \mathrm{M} / 8 \mathrm{~F}$ & Confirmed pulmonary sarcoidosis with CD4+ Iymphocytosis. \\
\hline $\begin{array}{l}\text { CD4+ Lymphocytosis (Group } \\
\text { 2) } n=16\end{array}$ & $\begin{array}{c}32-74 \\
(56.9 \pm 13.2)\end{array}$ & $10 \mathrm{M} / 6 \mathrm{~F}$ & $\begin{array}{l}\text { CD4+ lymphocytosis, exclusion of a pulmonary sarcoidosis } \\
\text { diagnosis. Infectious pneumonitis }(n=3) \text {, drug-induced } \\
\text { pneumonitis }(n=1) \text {, T. canii pulmonary infection }(n=1) \text {, } \\
\text { histiocytosis } X(n=1) \text {, asbestosis }(n=1) \text {, extrinsic } \\
\text { allergic alveolitis }(n=1) \text {, asthma }(n=1) \text {, tuberculosis } \\
(n=1) \text { Wegener granuloma }(n=1) \text {, auto-immune } \\
\text { disease }(n=1) \text {, eosinophilic pleurisy }(n=1) \text {, } \\
\text { inconclusive }(n=3) \text {. }\end{array}$ \\
\hline $\begin{array}{l}\text { Other pathologies (Group 3) } \\
\quad \mathrm{n}=48\end{array}$ & $\begin{array}{c}1-88 \\
(54.2 \pm 17.3)\end{array}$ & $34 \mathrm{M} / 14 \mathrm{~F}$ & $\begin{array}{l}\text { Absence of CD4 Iymphocytosis aspergillosis }(n=1) \text {, } \\
\text { Hodgkin's Iymphoma }(n=1) \text {, tuberculosis }(n=1) \text {, } \\
\text { drug-induced pneumonitis }(n=2) \text {, bronchial diseases } \\
(n=2) \text {, extrinsic allergic alveolitis }(n=3) \text {, systemic } \\
\text { diseases }(n=3) \text {, chemotherapy }(n=3) \text {, extrapulmonary } \\
\text { sarcoidosis }(n=3) \text {, rheumatoid arthritis }(n=4) \text {, asthma } \\
(n=3) \text {, respiratory distress }(n=6) \text {, infectious } \\
\text { pneumonitis }(n=5) \text {, interstitial syndrome }(n=11) \text {. }\end{array}$ \\
\hline Controls (Group 4) $n=11$ & $\begin{array}{c}7-85 \\
(42.7 \pm 22.4)\end{array}$ & $6 \mathrm{M} / 5 \mathrm{~F}$ & $\begin{array}{l}\text { Controls. Normal BAL prescribed on the basis of suspect } \\
\text { chest X-ray. }\end{array}$ \\
\hline
\end{tabular}


Collected events were gated on the lymphocyte window using a morphology scattergram. Results were expressed as the percentage of lymphocytes expressing each of the membrane markers investigated.

\section{Statistical Analysis}

Quantitative data were fed to a PC computer using Microsoft Excel and GraphPad Prism (version 2.01; GraphPad Software Inc, San Diego, California) for statistical comparison between the different groups using Kolmogorov-Smirnov, ANOVA, and Student's t test.

\section{Acknowledgements}

The authors are grateful to Dr. Paul Montagne for his help with the statistics and to Ms. Christine Hunter for secretarial work.

\section{References}

Agostini C, Chilosi M, Zambello R, Trentin L, and Semenzato G (1993). Pulmonary cells in health and disease: Lymphocytes. Eur Respir J 6:1378-1401.

Brandtzaeg $P$ (1996). History of oral tolerance and mucosal immunity. Ann N Y Acad Sci 778:1-27.

Cepek KL, Wong DA, Brenner MB, and Springer TA (1995). CD103 $\left(\alpha^{\mathrm{E}}\right)$ cluster report. In: Schlossman SF, Boumsell L, Gilks W, Harlan JM, Kishimoto T, Morimoto C, Ritz J, Shaw S, Silverstein R, Springer T, Tedder TF, and Todd RF, editors. Leukocyte Typing V, vol 2. Oxford: Oxford University Press, 1666-1667.

Cerf-Bensussan N, Jarry A, Brousse N, Lisowska GB, GuyGrand D, and Griscelli C (1987). A monoclonal antibody (HML-1) defining a novel membrane molecule present on human intestinal lymphocytes. Eur J Immunol 17:1279-1285.

Chailleux E, Bignon JD, Peyrat MA, Godard A, and Soulillou JP (1985). Lymphocyte subsets, phytohaemagglutinin responsiveness of blood lymphocytes, and interleukin 2 production in sarcoidosis. Thorax 40:768-773.

Chen A, Engel P, and Tedder TF (1995). Structural requirements regulate endoproteolytic release of the L-selectin (CD62L) adhesion receptor from the cell surface of leukocytes. J Exp Med 182:519-530.

Chilosi M, Menestrina F, Capelli P, Montagna L, Lestani M, Pizzolo G, Cipriani, Agostini C, Trentin L, Zambello R, and Semenzato G (1988). Immunohistochemical analysis of sarcoid granulomas. Evaluation of $\mathrm{Ki} 67^{+}$and interleukin-1 ${ }^{+}$ cells. Am J Pathol 131:191-198.
Costabel U (1997). CD4/CD8 ratios in bronchoalveolar lavage fluid: Of value for diagnosing sarcoidosis? Eur Respir J 10:2699-2700.

Costabel U, Zaiss AW, and Guzman J (1992). Sensitivity and specificity of BAL findings in sarcoidosis. Sarcoidosis 9:211214.

Erle DJ, Brown T, Christian D, and Aris R (1994). Lung epithelial lining fluid $T$ cell subsets defined by distinct patterns of $\beta 7$ and $\beta 1$ integrin expression. Am J Respir Cell Mol Biol 10:237-244.

Jeffery PK and Corrin B (1984). Structural analysis of the respiratory tract. In: Bienenstock J, editor. Immunology of the lung and upper respiratory tract. New York: McGraw-Hill Book Company, 1-27.

Kolopp-Sarda MN, Béné MC, Massin N, Moulin JJ, and Faure GC (1994). Immunohistological analysis of macrophages, B-cells, and T-cells in the mouse lung. Anat Record 239:150-157.

Krug N, Tshernig T, Holgate S, and Pabst R (1998). How do lymphocytes get into asthmatic airways? Lymphocyte traffic into and within the lung in asthma. Clin Exp Allergy 28:10-18.

Merchant RK, Schwartz DA, Helmers RA, Dayton CS, and Hunninghake GW (1992). Bronchoalveolar lavage cellularity. The distribution in normal volunteers. Am Rev Respir Dis 146:448-453.

Nicod LP (1999). Pulmonary defence mechanisms. Respiration 66:2-11.

Pabst R and Gehrke I (1992). Is the bronchus associated lymphoid tissue (BALT) an integral structure of the lung in normal mammals, including humans? Am J Respir Cell Mol Biol 3:131-135.

Pabst $R$ and Tschernig T (1995). Lymphocytes in the lung: An often neglected cell. Numbers, characterization and compartmentalization. Anat Embryol 192:293-299.

Poulter LW, Rossi GA, Bjermer L, Costabel U, Israël-Biet D, Klech H, Pohl W, and Semenzato G (1992). The value of bronchoalveolar lavage in the diagnosis and prognosis of sarcoidosis. Eur Respir Rev 8:75-82.

Samet JM and Utell MJ (1991). The environment and the lung. JAMA 266:670-675.

Semenzato G (1991). Immunology of interstitial lung diseases: Cellular events take place in the lung of sarcoidosis, hypersensitivity pneumonitis and HIV infection. Eur Respir J 4:94-102.

Shaw SK and Brenner MB (1995). The beta 7 integrins in mucosal homing and retention. Semin Immunol 7:335-342. 